\title{
Gamma knife radiosurgery for thalamotomy in Parkinsonian tremor: a five-year experience
} Christopher M. Duma, M.D., Deane B. Jacques, M.D., Oleg Kopyov, M.D., Ph.D., Rufus J. Mark,
M.D., Brian Copcutt, Ph.D., and Halle K. Farokhi

The Neurosciences Institute and Department of Radiation Oncology, Good Samaritan Hospital, Los Angeles, California

Certain patients, for example elderly, high-risk surgical patients, may be unfit for radiofrequency thalamotomy to treat Parkinsonian tremor. Some patients, when given the opportunity, may choose to avoid an invasive surgical procedure. The authors retrospectively reviewed their experience using gamma knife radiosurgery for thalamotomies in this patient subpopulation.

Radiosurgical nucleus ventralis intermedius thalamotomy using the gamma knife unit was performed to make 38 lesions in 24 men and 10 women (median age 73 years, range 58-87 years) over a 5-year period. A median radiation dose of 130 Gy (range 100-165 Gy) was delivered to 38 nuclei (four patients underwent bilateral thalamotomy) using a single 4-mm collimator following classic anatomical landmarks. Twenty-nine lesions were made in the left nucleus ventralis intermedius thalamus for right-sided tremor. Patients were followed for a median of 28 months (range 6-58 months). Independent neurological evaluation of tremor based on the change in the Unified Parkinson's Disease Rating Scale tremor score was correlated with subjective patient evaluation. Comparison was made between a subgroup of patients in whom "low-dose" lesions were made (range 110-135 Gy, mean $120 \mathrm{~Gy}$ ) and those in whom "high-dose" lesions were made (range 140-165 Gy, mean $160 \mathrm{~Gy}$ ) for purposes of dose-response information.

Four thalamotomies $(10.5 \%)$ failed, four $(10.5 \%)$ produced mild improvement, $11(29 \%)$ produced good improvement, and $10(26 \%)$ produced excellent relief of tremor. In nine thalamotomies $(24 \%)$ the tremor was eliminated completely. The median time to onset of improvement was 2 months (range 1 week-8 months) Concordance between an independent neurologist's evaluation and that of the patient was statistically significant $(\mathrm{p}<0.001)$. Two patients who underwent unilateral thalamotomy experienced bilateral improvement of their tremor. There were no neurological complications. There was better tremor reduction in the high-dose group when compared with the low-dose group $(\mathrm{p}<0.04)$.

Although less effective than other stereotactic techniques, gamma knife radiosurgical thalamotomy offers tremor control with minimal risk to a patient population unsuited for open surgery.

Key Words * thalamotomy * Parkinson's disease * radiosurgery * gamma knife

The use of stereotactic radiosurgery for the treatment of functional disorders dates back as far as 1951, 
when the father of current day gamma knife radiosurgery, Lars Leksell, experimented with an orthovoltage $\mathrm{x}$-ray tube attached to his stereotactic arc-centered system to treat trigeminal neuralgia.[13] Difficulties in precise targeting for functional disorders without physiological feedback, however, caused interest in this technique to wane.

By the 1980s, radiofrequency thermocoagulation of various targets within the ventrolateral thalamus had become the preferred method for the surgical amelioration of movement disorders related to Parkinson's disease (PD).[2,3,12,19] By this time the prototype gamma unit developed in 1968 had been used for years to treat arteriovenous malformations and trigeminal neuralgia, and more investigators had acquired a sound knowledge of the radiobiology of single fraction radiosurgery. Still no means existed to monitor intraoperative physiological feedback, however, and thus experience with functional radiosurgery began slowly.[1,4,23]

There is a subgroup of patients with PD who have conditions that predispose them to the risks of invasive stereotactic neurosurgery. These are patients who are receiving a course of anticoagulant drugs, have respiratory or cardiac disease, are very elderly, or who are in general poor risks for invasive surgery. In addition, some patients may choose a less invasive alternative when offered the option. Radiosurgery does not involve opening of the cranium or incisions. The risk of hemorrhage from passing an electrode to the depths of the thalamus is eliminated and so is the potential risk of meningitis from operative infection. We believe that for these reasons stereotactic radiosurgical thalamotomy has value in a small subgroup of patients. Our 5-year experience using gamma knife radiosurgical thalamotomy in 34 patients is described and a comparison between "low-dose" radiosurgical lesions and "high-dose" radiosurgical lesions is discussed.

This retrospective review represents the largest reported series of patients who have undergone gamma knife radiosurgery for thalamotomy with the longest median follow up. Included in this review are seven patients described by us in a previous communication.[21] The goals of our study were: 1) to determine the efficacy of the procedure; 2) to see if there is a dose-response relationship; 3) to review the radiological findings of radiosurgical lesioning; and 4) to assess the risks of complications.

\section{CLINICAL MATERIAL AND METHODS}

\section{Patient Selection}

Between March 1991 and December 1996, 34 patients (24 men and 10 women) with disabling tremor due to PD that was refractory to medical therapy underwent stereotactic radiosurgery using the 201-source ${ }^{60}$ Co gamma knife unit at Good Samaritan Hospital in Los Angeles, California. Four patients underwent bilateral procedures for a total of 38 lesions. Twenty-nine lesions were placed on the left side for right-sided tremor. No patient underwent prior surgery for their PD symptoms.

For purposes of dose-response comparison, two treatment subgroups were retrospectively defined. Sixteen patients (43\%) were considered to have received "high-dose" lesions (mean maximum target dose 160 Gy, range 140-165). Twenty-two patients (57\%) were considered to have received "low-dose" lesions (mean $120 \mathrm{~Gy}$, range 110-135 Gy).

Patients were accepted for radiosurgery if they did not satisfy the criteria for invasive radiofrequency thalamotomy because they represented a poor surgical or anesthetic risk, were too advanced in age, used anticoagulant agents, or if they perferred a less invasive treatment method (Table 1). The Unified 
Parkinson's Disease Rating Scale (UPDRS)[5] was used to assess the patients pre- and postoperatively. Only patients with UPDRS Grade 3 or 4 tremor were chosen for treatment.

\begin{tabular}{|c|c|}
\hline \multicolumn{2}{|c|}{$\begin{array}{c}\text { TABLE } 1 \\
\text { SUMMARV OF CL NICAL CONDITIONS PREDISPOSNG PATIENTS TO } \\
\text { GAMMA KN FE THALAMOTOMN }\end{array}$} \\
\hline Condidition & No. of Patierts \\
\hline $\begin{array}{l}\text { patient choice } \\
\text { recei ving anticoagulant agents } \\
\text { advanoed age } \\
\text { severe cardiopulmonary disease } \\
\text { mild dementia. }\end{array}$ & $\begin{array}{r}18 \\
5 \\
5 \\
4 \\
2\end{array}$ \\
\hline
\end{tabular}

\section{Surgical Procedure}

Target localization of the nucleus ventralis intermedius (VIM) thalamus was determined by coordinates based on the position of the nucleus relative to the anterior commissure-posterior commissure (AC-PC) line, anatomical information gathered from very high resolution magnetic resonance (MR) imaging and subjective surgeon correlation with the Schaltenbrand and Wahren atlas.[22] The 50\% isodose line of the 4-mm collimator was placed medially at the edge of the contralateral internal capsule (Fig. 1 left). The average target coordinates for all thalamotomies in this series were $\mathrm{x}=15 \mathrm{~mm}$ lateral to the AC-PC line, $\mathrm{y}=6 \mathrm{~mm}$ posterior to the midpoint of the AC-PC line, and $\mathrm{z}=4 \mathrm{~mm}$ superior to the AC-PC line.

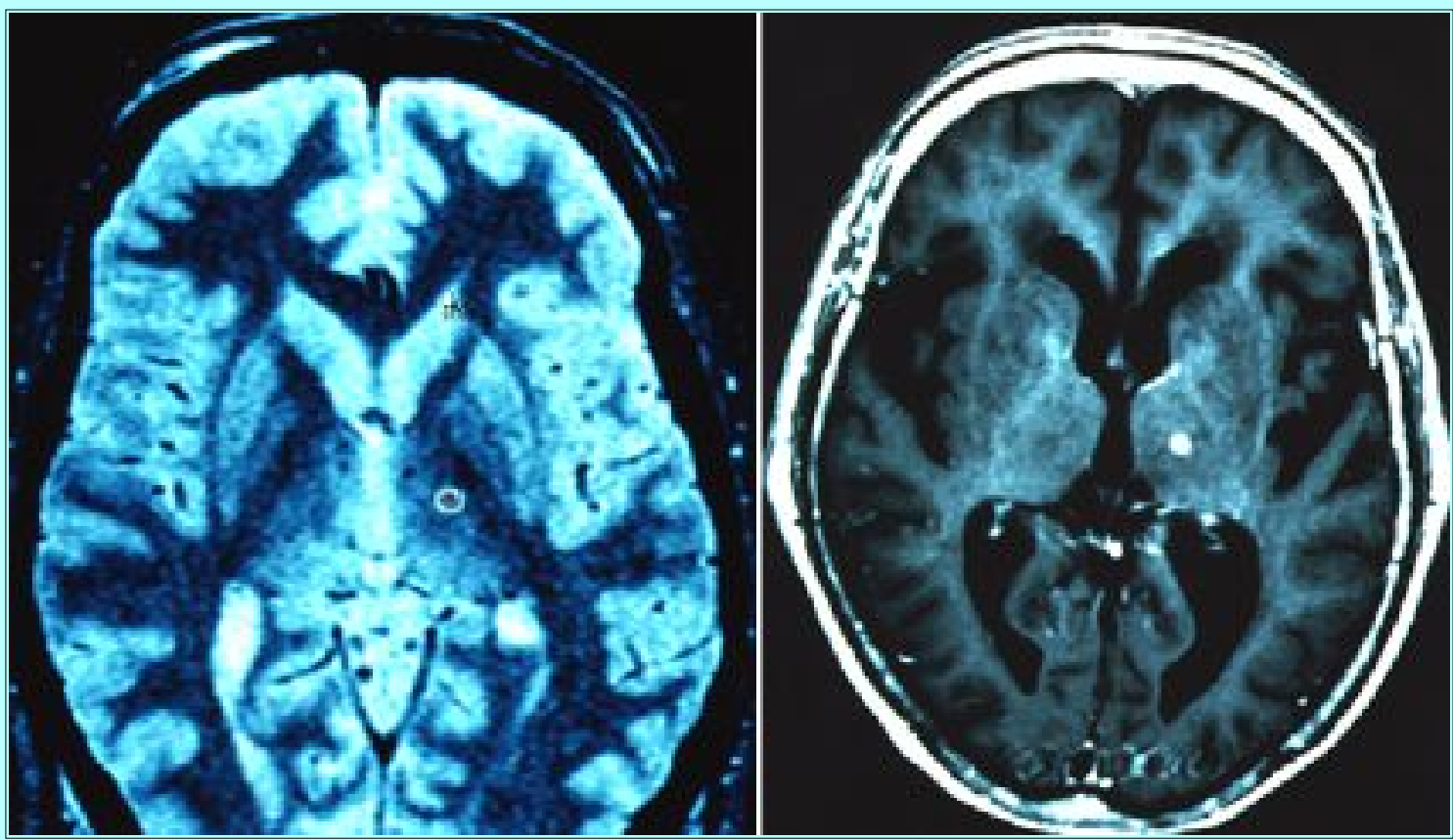

Fig. 1. Left: Computer-generated stereotactic VIM target planning in the axial plane. Right: Magnetic resonance image showing radiosurgical lesion (4-mm collimator, maximum dose $160 \mathrm{~Gy})$ at 6-month follow-up examination.

The Leksell G stereotactic coordinate frame (Elekta Instruments, Atlanta, Georgia) was attached to the patient's head and high-resolution MR images were obtained using 2-mm-thick slices in the axial and coronal planes. The $\mathrm{T}_{1}$ - and $\mathrm{T}_{2}$-weighted images were used for target localization. Single isocenter computer dose planning was performed using a commercially available software system (GammaPlan; Elekta Instruments). The maximum treatment dose with a single 4-mm collimator was determined jointly 
by the attending neurosurgeon, radiation oncologist, and medical physicist. The selection of the dose was guided by a dose-volume analysis based on prior experience with parenchymal tolerance to gamma knife radiosurgery. In selected cases one or more of the 201 collimator sources were blocked to reduce exposure to the lens.

Immediately after radiosurgery, all patients were given a single intravenous dose of $10 \mathrm{mg}$ of dexamethasone. All patients were discharged within 36 hours.

\section{Postoperative Neurological Examination}

Evaluations performed by an independent neurologist and UPDRS scoring of the patient's response to treatment were obtained at regular clinical follow-up intervals dictated by the referring neurologist. Each patient underwent 1-, 3-, and 6-month follow-up examinations by the treating neurosurgeons; however, these evaluations were not used in the outcome data. Patients were also asked to rate subjectively the percentage improvement in their tremor on a UPDRS-correlated improvement scale. Statistical correlation between patient and independent neurologist assessment of outcome was made using the Pearson correlation analysis. Clinical outcomes for low-dose and high-dose groups were analyzed using the Wilcoxon nonparametric test.

Mild improvement was categorized as a change of one UPDRS grade at each independent neurologist evaluation and a subjective patient response indicating a 1 to $33 \%$ improvement. Good improvement was categorized as a change of two UPDRS grades at each neurological evaluation and a subjective patient response indicating a 34 to $66 \%$ improvement. Excellent improvement was categorized as a change of three UPDRS grades and a subjective patient response indicating a 67 to $99 \%$ improvement (Table 2).

\begin{tabular}{|cc|}
\hline \multicolumn{2}{c|}{ TABLE 2 } \\
CORRELATION OF EYALUATIONS BV INDEPENDENT NEUROLOGISTS AND PATIENT \\
SELF-ASSESSMENT SCORES \\
\hline \hline \multicolumn{1}{c|}{$\begin{array}{cc}\text { Change in UPDRS Score } \\
\text { Reported by Neurologst }\end{array}$} & $\begin{array}{c}\text { Subjective Improvem ent } \\
\text { Reported By Patient }\end{array}$ \\
\hline 0 & none \\
1 & mild $(1-33 \%$ relief) \\
2 & good $(34-66 \%)$ \\
3 & exoellent $(67-99 \%)$ \\
3 or 4 & absent tremor \\
\hline
\end{tabular}

Follow-up MR imaging was performed at 3-month intervals for the first 6 months and then at 6-month intervals thereafter. Magnetic resonance imaging protocols included 2-mm high-resolution axial and coronal $\mathrm{T}_{1}$ - and $\mathrm{T}_{2}$-weighted images with and without gadolinium enhancement. Differences in the MR imaging lesion size between the low-dose $(120 \mathrm{~Gy})$ and high-dose $(160 \mathrm{~Gy})$ groups were analyzed using the unpaired t-test, analysis of variance, and the Wilcoxon nonparametric test.

\section{RESULTS}

\section{Tremor Relief}

Clinical and radiological follow-up periods ranged from 6 to 58 months (median 28 months). Changes in clinical tremor as determined by the UPDRS delta score assigned by the neurologists and by the subjective patient scoring were highly correlated: 0.89 (Pearson correlation coefficient, $\mathrm{p}<0.001$ ). 
No change in tremor occurred in four patients (10.5\%), mild improvement was seen in four (10.5\%), good improvement was seen in 11 (29\%), and excellent improvement in 10 (26\%). In nine patients (24\%), the tremor was eliminated completely. The high-dose thalamotomy lesion was more effective in reducing tremor (78\% mean improvement) than the low-dose lesion (56\% mean improvement) ( $\mathrm{p}<0.04$, Wilcoxon nonparametric test; Fig. 2).

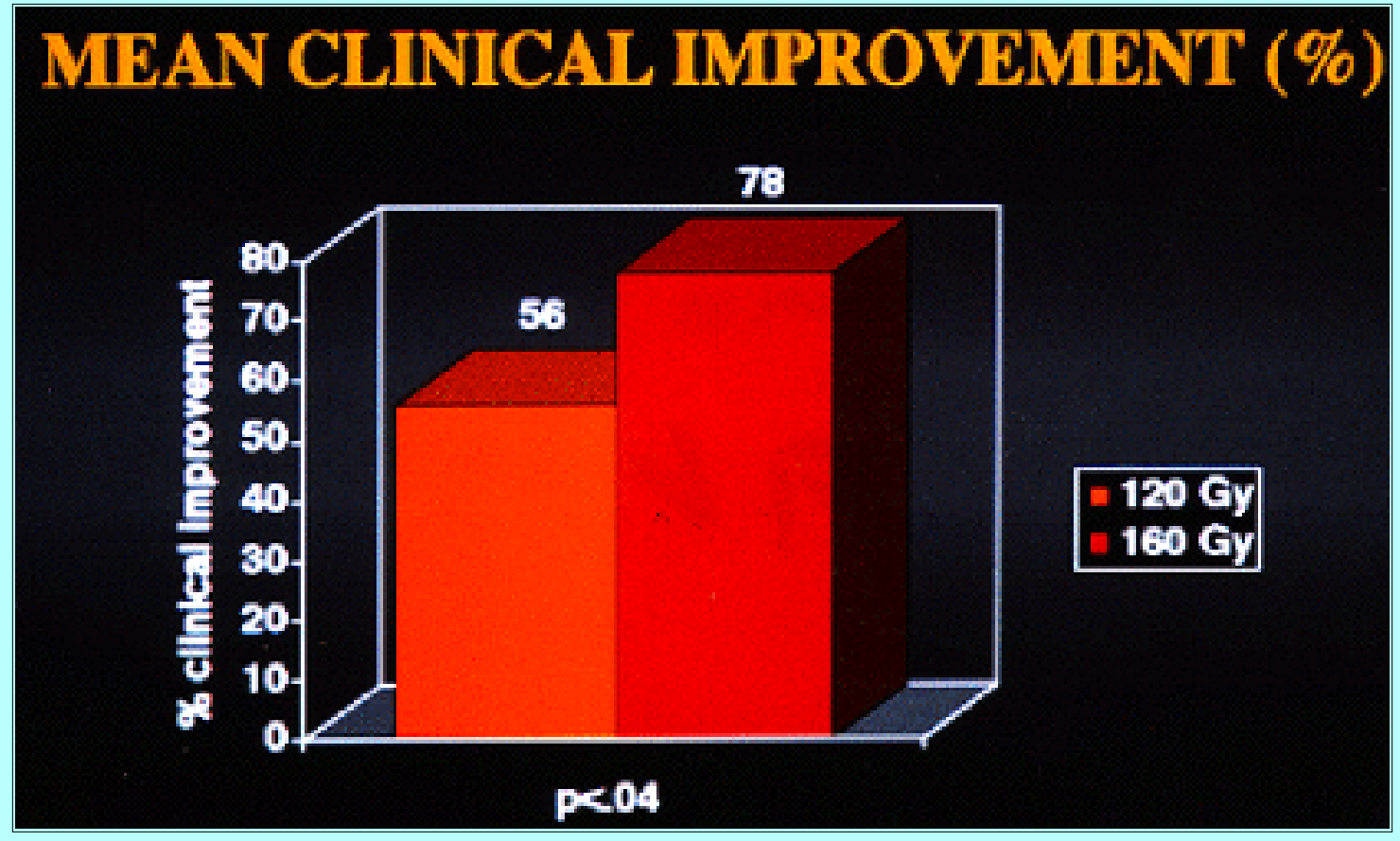

Fig. 2. Bar graph showing percentage improvement in tremor between high- and low-dose treatment groups. The high-dose group (mean $160 \mathrm{~Gy}$, range 140-165 Gy) had significantly better tremor control than the low-dose group (mean $120 \mathrm{~Gy}$ ) (p lt 0.04).

The median time to onset of improvement was 2 months (range 1 week- 8 months). Two patients who underwent unilateral thalamotomy experienced bilateral improvement of their tremor. Two patients who had initial improvement in their tremors but who eventually returned to baseline at their follow-up examinations were included in the treatment failure group. All other patients maintained their level of improvement throughout the course of the follow up. There were no neurological complications.

\section{Radiological Findings}

Magnetic resonance imaging revealed a circumscribed spherical lesion that enhanced with administration of gadolinium on $\mathrm{T}_{1}$-weighted images at a median of 3 months after radiosurgical lesioning and a mildly diffuse $\mathrm{T}_{2}$-weighted signal change, representing edema, that usually followed white matter tracts at a median of 4.5 months following treatment.

The average $\mathrm{T}_{1}$-weighted gadolinium-enhanced lesion size was not different for the low- and high-dose groups and ranged from 3 to $6 \mathrm{~mm}$ (mean 5) at a median follow-up time of 6 months. This lesion was present on follow-up images at up to 58 months. 

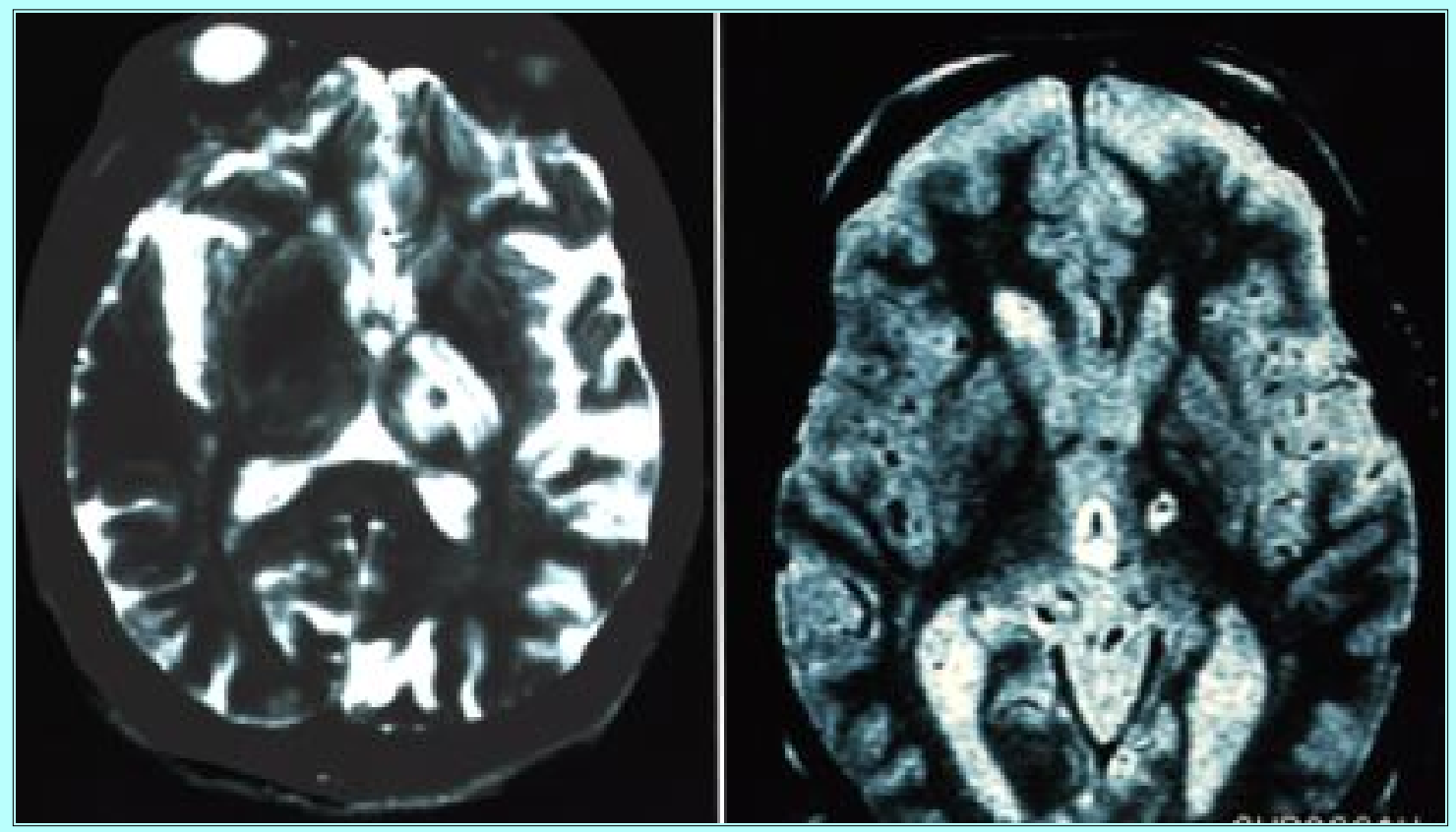

Fig. 3. Magnetic resonance $\mathrm{T}_{2}$-weighted image sequences at 6-month follow-up examination showing a comparison of the extremes of edema patterns between the high-dose (left) and the low-dose (right) groups. Note the white matter streaking seen in the high-dose group. The tremor had disappeared in the patient on the left, and there were no clinical sequelae of the $\mathrm{T}_{2}$-weighted changes.

The average $T_{2}$-weighted lesion size was not different for the low- and high-dose groups and ranged from 6 to $22 \mathrm{~mm}$ (mean 9.2) at a median of 6 months follow-up time. This lesion also persisted on future MR images (Fig. 3). Although there was a trend toward more edema in the high-dose treatment group, the differences in the $T_{1}$ and $T_{2}$-weighted images of the thalamic lesions between the two groups were not significant (Fig. 4). 


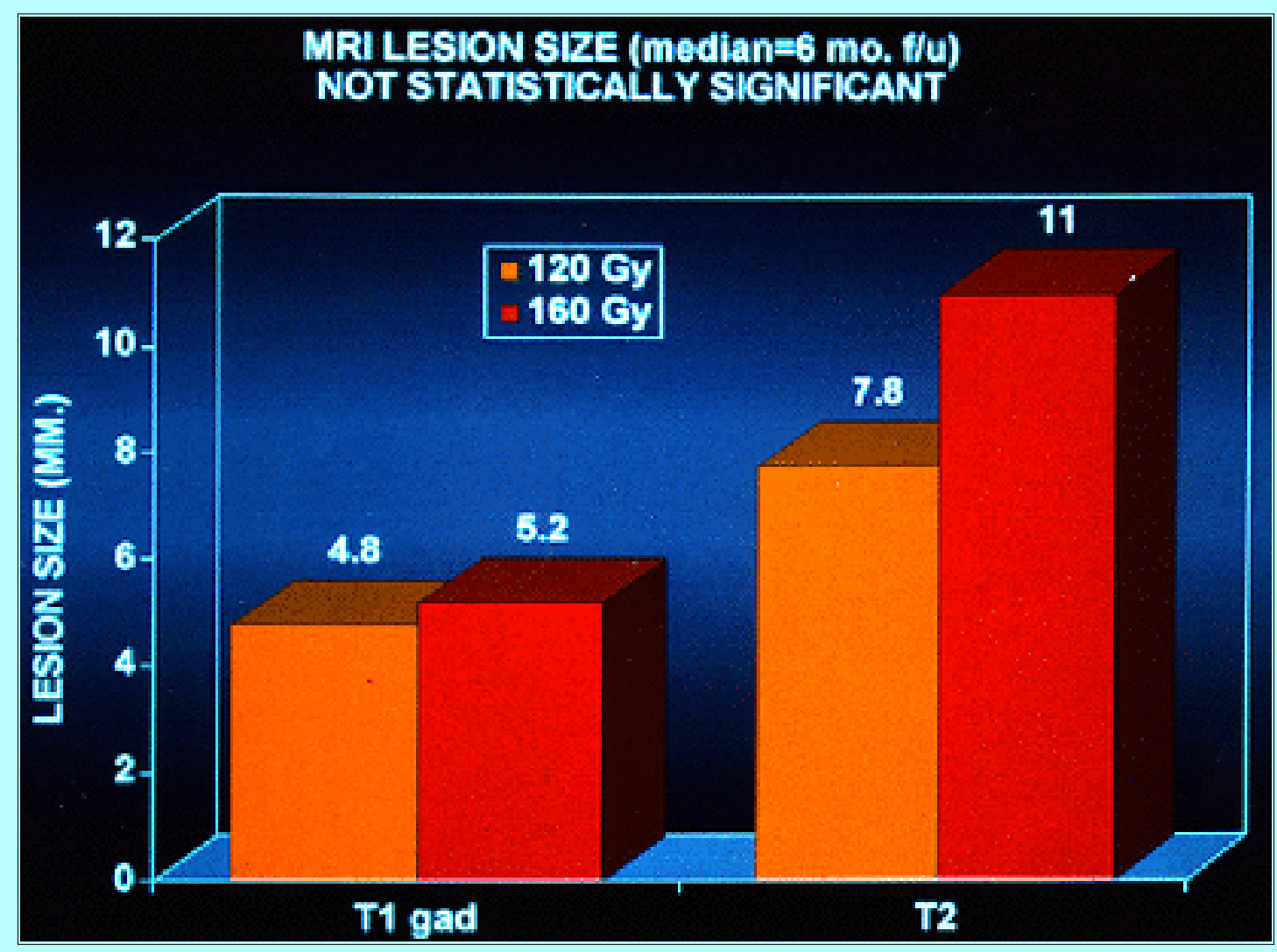

Fig. 4. Bar graph showing data on lesion sizes in the low- and high-dose groups on $\mathrm{T}_{1}$-weighted sequences with gadolinium enhancement and on $\mathrm{T}_{2}$ weighted sequences. There was no significant difference. (The mean diameter of the $T_{1}$-weighted sequences was $4.8 \pm$ $0.6 \mathrm{~mm}$ and $5.2 \pm 0.7 \mathrm{~mm}$, respectively; the mean diameter on the $\mathrm{T}_{2}$-weighted sequences was $7.8 \pm 1.3 \mathrm{~mm}$ and $11 \pm 4.2 \mathrm{~mm}$, respectively.)

\section{DISCUSSION}

\section{Tremor Relief}

This series consists of the largest number of patients undergoing radiosurgery for thalamotomy in whom significant follow up has been obtained. Overall, $34(89 \%)$ of 38 radiosurgically placed thalamic lesions were effective in reducing or eliminating tremor. In $24 \%$ of patients the tremor was abolished completely, and in another 55\% the patients attained an average 2 to 3 grade improvement of their UPDRS score. Evaluations by independent neurologists were highly correlated with subjective patient reports. No complications occurred.

Our results are similar to those reported in the late 1980s in which two patients were treated using the gamma knife.[17] In the first patient, a dose of $180 \mathrm{~Gy}$ with an 8-mm collimator was used. This patient had complete relief of his tremor 1 month after lesioning. Unfortunately 6 months later a right-sided hemiparesis and dysphasia developed. After receiving a course of steroid medication the patient had a mild hemiparesis and no tremor. The second patient received 200 Gy with a single 4-mm collimator and obtained only transient relief of the tremor.

Friehs, et al.,[6] treated three patients using a single 4-mm collimator with a maximum dose of $160 \mathrm{~Gy}$. All three patients showed a good response 3 or 4 weeks postradiosurgery with partial or complete resolution of their tremor; however, the follow-up period was only 1 year. 
Hirato, et al,[7] treated one patient using gamma knife thalamotomy with a maximum dose of $150 \mathrm{~Gy}$. The patient noted improvement in her tremor 3 months after treatment; the tremor was markedly diminished 6 months later without complications.

\section{Patient Selection}

Of the 900 patients treated using gamma knife radiosurgery at Good Samaritan Hospital in Los Angeles over the past 5 years, thalamotomies represent only $4.5 \%$ of the total cases. They also represent only $8 \%$ of the total number of cases of PD treated at our institution. Our treatment of parkinsonian tremor using radiofrequency lesioning with unit cell recording and physiological feedback results in $90 \%$ complete tremor relief, with less than a $3 \%$ morbidity rate. This is usually our procedure of choice for this group of patients. This retrospective review proved that for a small subset of patients who are not normally considered for surgical intervention or who chose this course of treatment, gamma knife thalamotomy has value.

\section{Target Selection}

As our electrophysiological knowledge of the basal ganglia has increased, target selection has changed to reflect this experience.[18] Initially, the efferent pathway from the globus pallidus to the ventralis anterialis oralis of the thalamus was thought to be the prime target for tremor elimination. Since then lesions have been moved posteriorly to the VIM for selective thalamotomy for tremor.[8,9,20,24]

Landmarks around the AC-PC line were used to target the contralateral VIM nucleus. In addition, subjective, visual inspection of MR images and Schaltenbrand and Bailey atlas[22] (anatomical landmarks) were also used in the decision-making process for target placement to account for anatomical variation in individual patients. Two-millimeter-thick MR slices with $\mathrm{T}_{2}$-weighted sequences gave excellent gray and white matter differentiation, which we found correlated well with surgical anatomy. Follow-up MR imaging showed that the planned targets and the actual lesions coincided, and that the lesioning did not impinge on the internal capsule.

\section{Collimator and Dose Selection}

Leksell and colleagues[13-15] and Lindquist and coworkers[16,17] have described necrotic lesions from their early experience with functional radiosurgery. They believed that maximum doses of 160 to $200 \mathrm{~Gy}$ were effective in creating a permanent necrotic lesion. Based on complications experienced in their early use of radiosurgery, they also sought to avoid large collimators.

Because the clinical nature of the radiosurgical lesioning was not yet well known in our early experience, we tended toward using smaller maximum doses for reasons of patient safety. Based on reports of the reliability of 4-mm collimator radiation administered in the rat brain and its dose-response relationship for the parenchyma,[10] patients treated later in our experience tended to receive higher radiosurgical doses. These two groups served as an excellent dose-response comparison paradigm. As time went on more experimental information became available. Kondziolka and Lunsford[10] reported their results in experimental rat brain lesioning and baboon brain lesioning, and our dose to the thalamus was increased with the hope of improved clinical effect.

In our series, 22 thalamotomies were performed using an average maximum dose of 120 Gy and 16 thalamotomies were performed using an average dose of $160 \mathrm{~Gy}$. Good, excellent, and complete improvement was better in the high-dose group (79\%) than in the low-dose group $(56 \%)(\mathrm{p}<0.04)$. 
There were no complications related to dosing.

\section{Radiological Findings}

Gadolinium-enhanced $\mathrm{T}_{1}$-weighted $\mathrm{MR}$ sequences revealed that the size of the radiosurgical lesions for the high- and low-dose groups was not statistically different and that they were consistent between patients. This was not the case in the $\mathrm{T}_{2}$-weighted sequences. Although the difference did not reach statistic significance, there was a trend for the higher-dose lesions to elicit a larger $\mathrm{T}_{2}$-weighted signal change or $\mathrm{T}_{2}$ "streaking" (Fig. 4). This streaking may represent edema, radiation change, demyelinization, or necrosis. It is unlikely that it represents necrosis in that the presence of the streaking within the capsule or other thalamic nuclei never correlated with neurological impairment. In addition, this streaking did not create mass effect. Only postmortem studies will elucidate the true nature of this interesting finding. Clinical improvement in the higher-dose group may be explained by a physiologically larger lesion in this group correcting any target planning inaccuracies.

\section{CONCLUSIONS}

Gamma knife radiosurgery for thalamotomy is an effective and useful alternative to invasive radiofrequency techniques in patients at high risk for surgery. The mechanical accuracy of the gamma unit combined with the anatomical accuracy of high-resolution MR imaging make radiosurgical lesioning safe and precise. Higher radiosurgical doses are more effective than lower ones at eliminating or reducing tremor and may be performed without complications.

\section{References}

1. Barcia Salorio JL, Roldan P, Hernandez G, et al: Radiosurgical treatment of epilepsy. Appl Neurophysiol 48:400-403, 1985

2. Cooper IS, Bravo G: Chemopallidectomy and chemothalamectomy. J Neurosurg 15:244-250, 1958

3. Cooper IS, Bravo GJ: Implications of a five-year study of 700 basal ganglia operations. Neurology 8:701-707, 1958

4. Dahlin H, Larsson B, Leksell L, et al: Influence of absorbed dose and field size on the geometry of the radiation-surgical brain lesion. Acta Radiol Ther Phys Biol 14:139-144, 1975

5. Fahn S, Elton RL, members of the UPDRS Development Committee: Unified Parkinson's disease rating scale, in Fahn S, Marsden CD, Goldstein M, et al (eds): Recent Developments in Parkinson's Disease, ed 2. New York: MacMillan, 1987, pp 153-163

6. Friehs GM, Ojakangas CL, Pachatz P, et al: Thalamotomy and caudatotomy with the gamma knife as a treatment for parkinsonism with a comment on lesion sizes. Stereotact Funct Neurosurg 64 (Suppl 1):209-221, 1995

7. Hirato M, Ohye C, Shibazaki T, et al: Gamma knife thalamotomy for the treatment of functional disorders. Stereotact Funct Neurosurg 64 (Suppl 1):164-171, 1995

8. Jankovic J, Cardoso F, Grossman RG, et al: Outcome after stereotactic thalamotomy for parkinsonian, essential, and other types of tremor. Neurosurgery 37:680-687, 1995 
9. Kelly PJ, Ahlskog, JE, Goerss SJ, et al: Computer-assisted stereotactic ventralis lateralis thalamotomy with microelectrode recording control in patients with Parkinson's disease. Mayo Clin Proc 62:655-664, 1987

10. Kondziolka D, Linskey ME, Lunsford LD: Animal models in radiosurgery, in Alexander E III, Loeffler J, Lunsford LD (eds): Stereotactic Radiosurgery. New York: McGraw-Hill, 1993, pp 51-64

11. Kondziolka D, Lunsford LD, Flickinger JC, et al: Stereotactic radiosurgery for trigeminal neuralgia: a multiinstitutional study using the gamma unit. J Neurosurg 84:940-945, 1996

12. Laitinen LV: Brain targets in surgery for Parkinson's disease. Results of a survey of neurosurgeons. $\mathbf{J}$ Neurosurg 62:349-351, 1985

13. Leksell L: Cerebral radiosurgery. I. Gamma thalamotomy in two cases of intractable pain. Acta Chir Scand 134:585-595, 1968

14. Leksell L: The stereotaxic method and radiosurgery of the brain. Acta Chir Scand 102:316-319, 1951

15. Leksell L, Backlund EO: Stereotactic gammacapsulotomy, in Hitchcock ER, Ballantine HT Jr, Meyerson BA (eds): Modern Concepts in Psychiatric Surgery. Amsterdam: Elsevier, 1979, pp 213-216

16. Lindquist C, Kihlstrom L, Hellstrand E: Functional neurosurgery--a future for the gamma knife? Stereotact Funct Neurosurg 57:72-81, 1991

17. Lindquist C, Steiner L, Hindmarsh T: Gamma knife thalamotomy for tremor: report of two cases, in Steiner L (ed): Radiosurgery, Baseline and Trends. New York: Raven Press, 1992, pp 37-243

18. Meyers HR: Surgical procedure for postencephalitic tremor with notes on the physiology of premotor fibers. Arch Neurol Psychiatry 44:453-459, 1940

19. Ohye C: Selective thalamotomy for movement disorders: microrecording stimulation techniques and results, in Lunsford LD (ed): Modern Stereotactic Neurosurgery. Boston: Martinus Nijhoff, 1988, pp $315-331$

20. Otsuki T, Jokura H, Takahashi K, et al: Stereotactic y-thalamotomy with a computerized brain atlas: technical case report. Neurosurgery 35:764-768, 1994

21. Rand RW, Jacques DB, Melbye RW, et al: Gamma knife thalamotomy and pallidotomy in patients with movement disorders: preliminary results. Stereotact Funct Neurosurg 61(Suppl 1):65-92, 1993

22. Schaltenbrand G, Wahren W: Atlas for Stereotaxy of the Human Brain. Chicago: Year Book Medical, 1977, Plates 16-18

23. Steiner L, Forster D, Leksell L, et al: Gammathalamotomy in intractable pain. Acta Neurochir 52:173-184, 1980

24. Tasker RR: Thalamotomy. Neurosurg Clin North Am 1:841-864, 1990

Manuscript received January 14, 1997. 
Accepted in final form February 22, 1997.

Address reprint requests to: Christopher M. Duma, M.D., The Neurosciences Institute, Good Samaritan Hospital, 1225 Wilshire Boulevard, Los Angeles, California 90017. 